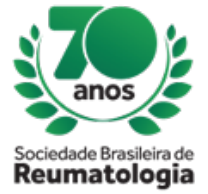

\title{
ASSOCIATION OF MYOSITIS AND SYSTEMIC LUPUS ERYTHEMATOSUS - CASE REPORT
}

Lígia Lavezo Ferreira (Universidade Brasil, Fernandópolis , SP, Brasil), Vislaine Aguiar Morete (Universidade Brasil, Fernandópolis, SP, Brasil), Carolina Pellison Carvalho (Universidade Brasil, Fernandópolis, SP, Brasil), Otavio Leão da Silveira (Universidade Brasil, Fernandópolis, SP, Brasil), Márcio César Reino Gaggini (Universidade Brasil, Fernandópolis, SP, Brasil), Aparecida Meira da Silva (Universidade Brasil, Fernandópolis, SP, Brasil), Taisa Morete da Silva (famerp 2019, famerp vestibular, famerp residencia medica FAMERP - Faculdade de Medicina de São José do Rio Preto, Fernandópolis, SP, Brasil)

\section{BACKGROUND}

Systemic lupus erythematosus (SLE) is a severe autoimmune disease, with many clinical manifestations. Myositis has traditionally been recognized as a feature in SLE, and it is a heterogeneous condition. Clinical manifestations include muscle weakness associated with increased levels of creatine phosphokinase (CPK).

\section{CASE REPORT}

A 38-year-old woman, attended the rheumatology clinic of Universidade Brasil, complaining of migratory and asymmetric polyarthralgia, without morning stiffness, which 3 months ago has evolved to loss of strength of the scapular and pelvic girdle. At clinical examination, was observed strength grade 3 in upper limbs and grade 4 in lower limbs; without phlogistic signs in joints. Laboratory tests showed positive antinuclear factor (ANF), with coarse speckled pattern (1:640), CPK of $6416 \mathrm{U} / \mathrm{L}$, erythrocyte sedimentation rate (ESR) of $90 \mathrm{~mm}, \mathrm{C}$-reactive protein (PCR) of $31.2 \mathrm{mg} / \mathrm{L}$, oxaloacetic transaminase (GOT) of $198 \mathrm{U} / \mathrm{L}$, Glutamate-Pyruvate Transaminase (GPT) of $184 \mathrm{U} / \mathrm{L}$, Lactic Acid Dehydrogenase (LDH) of 1636 $\mathrm{U} / \mathrm{L}$, Aldolase of $23.5 \mathrm{U} / \mathrm{L}$, and computed tomography (CT) showed right pleural effusion. The diagnostic hypothesis was polymyositis and lupus. Treatment was performed with methylprednisolone pulse therapy for 3 days, with significant improvement of the symptoms, with significant improvement of the symptoms, being discharged with prednisone $60 \mathrm{mg}$ prednisone a day. Moreover, the patient presented results of the Anti-SM reagent and complement consumption of $\mathrm{C} 3, \mathrm{C} 4$ and $\mathrm{CH} 50$. Treatment with hydroxychloroquine and methotrexate was started, presenting symptom control.

\section{CONCLUSION}

True myositis is relatively rare and failure to identify in cases of SLE, with a the prevalence varies from $4 \%$ to $16 \%$ in SLE. The significant association of active disease with myositis suggests that organ damage promote the progression of myositis in lupus patients. 